\title{
ABBREVIATIONS OF ANCIENT AUTHORS
}

Anth. Lat. Anthologia Latina

Appian

Pun. Punic Wars

Apuleius

De Deo Soc. De Deo Socratis

Met. Metamorphoses

Aristides

Or. Orationes

Arnobius

Adv. Nat. Adversus Nationes

Asc. Asconius

Mil. Commentary on Cicero, Pro Milone

Augustine

De Civ. D. De Civitate Dei

Cato

Agr. De Agricultura

Catullus

Carm. Carmina

Censorinus

DN. De die natale

Cic. Cicero

Att. Epistulae ad Atticum

Brut. Brutus

Cael. Pro Caelio

Clu. Pro Cluentio

Div. De Divinatione

Fin. De Finibus

Flac. Pro Flacco

Leg. De Legibus 
Marcell. Pro Marcello

Mil. Pro Milone

Phil. Philippic

Pis. In Pisonem

Rab. Perd. Pro Rabirio Perduellionis Reo

Rep. De Re Publica

Scaur. Pro Scauro

Tusc. Tusculunae Disputationes

Vat. In Vatinium

Verr. In Verrem

Dig. Digest

Dion. Hal. Dionysius of Halicarnassus

Ant. Rom. Antiquitates Romanae

Donatus

Ter., Adelph Commentum Terenti, Adelphi

Phormio Commentum Terenti, Phormio

Eusebius

Hist. Eccl. Historia Ecclesiastica

Gaius

Inst. Institutiones

Gell. Aulus Gellius, Noctes Atticae

Horace

Carm. Carmina

Epist. Epistles

Epod. Epodes

Sat. Satires

Juv. Juvenal

Sat. Saturae

Lucan

BC. De Bello Civili

Lucr. Lucretius

Macrobius

Sat. Saturnalia

Minicius Felix

Oct. Octavius

Non. Marc. Nonius Marcellus, De Conpendiosa Doctrina Ovid

Am. Amores

Ars Am. Ars Amatoria

Her. Heroides 
Met. Metamorphoses

Trist. Tristia

Persius

Sat. Saturae

Petronius

Sat. Satyricon

Plaut. Plautus

Amph. Amphitruo

Aul. Aulularia

Curc. Curculio

Men. Menaechmi

Merc. Mercator

Mostell. Mostellaria

Poen. Poenulus

Pliny (the Elder)

HN. Naturalis Historia

Pliny (the Younger)

Ep. Epistulae

Plutarch

Rom. Romulus

Vit. C. Gracch. Vita Gaius Gracchus

Porphyrio

Epist. Commentum in Horatium Flaccum, Epistulae

Epod. Commentum in Horatium Flaccum, Epodi

Porphyry

Abst. De Abstinentia

Prudentius

C. Symm. Contra Symmachum

Pseudo-Acro

Epist. Commentum in Horatium Flaccum, Epistulae

Quintilian

Inst., Prooem. Institutio oratoria, Prooemium

Seneca (the Elder)

Contr. Controversiae

Seneca (the Younger)

Apocol. Apocolocyntosis

Ep. Epistulae

Servius

Aen. In Vergilium Commentarius, Aeneis

Georg. In Vergilium Commentarius, Georgica 
Statius

Ach. Achilleis

Silv. Silvae

Theb. Thebais

Suet. Suetonius

Calig. Gaius Caligula

Jul. Divus Julius

Tib. Tiberius

Tacitus

Agr. Agricola

Ann. Annales

Hist. Historiae

Val. Max. Valerius Maximus

Varro

Ling. De Lingua Latina

Virgil

Aen. Aeneid 